ASTHMA

\title{
Involvement in treatment decisions: what do adults with asthma want and what do they get? Results of a cross sectional survey
}

\author{
A-L Caress, K Beaver, K Luker, M Campbell, A Woodcock
}

Thorax 2005;60:199-205. doi: 10.1136/thx.2004.029041

See end of article for authors' affiliations

......................

Correspondence to: Dr A-L Caress, School of Nursing, Midwifery and Social Work, University of Manchester, Oxford Road, Manchester M13 9PL, UK; ann.caress@manchester. ac.uk

Received 22 May 2004 Accepted 14 October 2004

\begin{abstract}
Background: Current healthcare policy advocates patient participation in treatment decision making. However, in asthma there is little evidence regarding patients' views on such involvement. This study explored the preferred and perceived level of involvement in treatment decisions, rationales for role preference, perceived facilitators of/barriers to involvement, and the interrelationship of role preference and demographic variables in a sample of patients with asthma.

Methods: A cross sectional survey was performed of 230 adults with clinician diagnosed asthma from 10 primary care sites and one specialist respiratory centre in north-west England. Preferred role in treatment decisions was assessed using the Control Preferences Scale.

Results: Fifty five (23.9\%) preferred an active role, $82(35.7 \%)$ a collaborative role, and $93(40.4 \%)$ a passive role; $19(8.2 \%)$ perceived their role as active compared with $45(19.6 \%)$ collaborative and 166 $(72.2 \%)$ passive. Only $33.5 \%(n=77)$ of respondents attained their most preferred role; $55.2 \%(n=127)$ were less involved than they preferred. Patient related, professional related, and organisational factors, especially quality and duration of consultations, facilitated or hampered involvement. Role preferences were not strongly associated with demographic variables or asthma severity.

Conclusions: This study in patients with asthma highlights the fact that there is a need for professional and patient education regarding partnership working, skilful communication, and innovative approaches to service delivery.
\end{abstract}

A sthma patients can have considerable input into the management of their condition, often engaging in some degree of independent decision making ${ }^{2}$-for example, adjustment of treatment by following a personalised written asthma action plan.

There is increasing emphasis on providing services responsive to patients' needs and preferences. ${ }^{3}{ }^{4}$ Equally, there is recognition that those with long term illnesses may be able to contribute to the conduct of a treatment regimen and participate in treatment decisions..$^{3-5}$ There is good evidence in asthma that actively involving patients in care and treatment decision making improves outcomes. ${ }^{126}$

While the desired level of participation in treatment decisions has been widely explored in some conditions, notably cancer, ${ }^{3}{ }^{4-9}$ it is less well explored in other long term health problems - a notable omission since the satisfaction of these patients and their engagement with their treatment regimen are crucial to its long term maintenance. In asthma, other than our own prior exploratory work, ${ }^{10}$ only two studies $^{11} 12$ have specifically addressed patients' preferred level of involvement in treatment decisions. At present we therefore have only a poor understanding of the decision making role preferences of patients with asthma and, importantly, of the reasons why they prefer particular roles in treatment decisions, whether these preferences can be predicted by, for example, demographic variables and the extent to which patients' preferences are met. The present study therefore sought to build on our earlier exploratory work with a more in-depth exploration of asthma patients' role preferences and the contributors to these.

\section{METHODS}

Study design and aims

The study was a cross sectional survey. Its aims were:
- to identify patients' preferred level of involvement in treatment decision making-that is, their decisional role preferences-and their rationales for these preferences;

- to identify patients' perceived level of involvement in treatment decision making;

- to assess congruence between patients' preferred and perceived roles in treatment decision making;

- to seek patients' views on facilitators of and barriers to their participation in treatment decisions; and

- to explore the relationship between decisional role preferences and demographic variables.

\section{Study sites and sample}

Patients were identified from asthma registers in 10 primary care sites and one specialist respiratory centre (2:1 ratio of primary care:specialist centre). Asthma affects adults of all ages and socioeconomic groups, ${ }^{6}{ }^{13-15}$ occurs in both ethnic majority and minority populations ${ }^{6}{ }^{16}{ }^{17}$ and, in adults, is more prevalent in women than in men. ${ }^{18}$ These considerations were borne in mind within our recruitment strategy. Our exploratory work ${ }^{10}$ had indicated that recruitment from socially deprived areas was likely to be difficult. In order to ensure that the sample recruited represented views of respondents from across the social spectrum, we overrepresented general practices from socially deprived areas (five of the 10 sites). Individuals from minority ethnic groups were included (provision having been made for use of bilingual workers if necessary). However, as the study localities had only small ethnic minority populations, we anticipated that patients from such groups would make up only a small percentage of the sample. Patients were stratified within each site by age, sex, and disease severity. 
If an individual declined to participate, a replacement from within the same stratum was identified in an endeavour to maintain balance across the strata. Inclusion criteria were age 18+; able to converse in English; clinician diagnosed asthma; prescription for at least bronchodilators in the last 12 months; non-smoker if aged 45 or over (to exclude possible COPD); no respiratory disease other than asthma.

Comparable studies in other conditions found that approximately $20 \%$ of respondents preferred an active decisional role. ${ }^{819}$ The nQuery Advisor software package for sample size calculation showed that estimation of the percentage of individuals selecting an active role to be $20 \%$ with a $95 \%$ confidence interval with half width of $\pm 5 \%$ would require a sample of at least 226 patients.

\section{Data collection methods and instrument}

Data were collected face to face using a previously piloted ${ }^{10}$ structured interview schedule whose main component was the well-validated Control Preferences Scale (CPS). ${ }^{7}$ Its transferability to asthma was assessed in our earlier exploratory work. ${ }^{10}$

The CPS comprises five vignettes, each presented on a sort card (box 1). The scale is underpinned by a theoretical model of participation as a continuum from active through collaborative to passive-hence the sort cards can be considered individually or in terms of one of these three role types. ${ }^{7}$ Respondents choose the more preferred from randomly presented pairs of cards until all possible pairings of the five sort cards have been seen and an hierarchical preference order (from most to least preferred role) has emerged. Data were collected regarding perceived role in decisions using a second set of sort cards from which the words "I prefer" were omitted. Respondents selected the one card which most closely reflected their perceived role. Additional data were collected by means of open ended questions regarding rationale for role preference, barriers to and facilitators of participation, and circumstances which might alter role preference; responses were recorded verbatim. These procedures have been applied successfully in

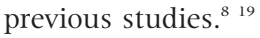

Demographic data collected were age, sex, socioeconomic status, $^{20}$ highest educational level, ethnicity (as stated by respondent), asthma severity, ${ }^{6}$ and duration of condition.

Box 1 The five vignettes which comprise the Control Preferences Scale (after Degner ${ }^{7}$ )

Active role options

(A) I prefer to make the final selection about which treatment I will receive.

(B) I prefer to make the final selection of my treatment after seriously considering my doctor's opinion.

Collaborative role option

(C) I prefer that my doctor and I share responsibility for deciding which treatment is best for me.

Passive role options

(D) I prefer that my doctor makes the final decision about which treatment will be used, but seriously considers my opinion.

(E) I prefer to leave all decisions regarding my treatment to my doctor.

\section{Data analysis}

Data were coded and entered into the SPSS statistical package (version 10.1). Data from open ended questions were thematically analysed ${ }^{21}$ and reduced prior to data entry. Decision making role preferences were reported as distributions based on whether an individual's choice conformed with an active, collaborative, or passive role in decision making (box 1). Validity of the CPS with the present sample was assessed using Coombs' unfolding theory ${ }^{72}$ via bespoke SAS software (SAS version 8). ${ }^{723}$ Inferential statistics $\left(\chi^{2}\right.$ test for trend, Kendall's tau $\mathrm{b}_{\mathrm{b}}$ Cohen's kappa) were used to compare the most preferred and perceived role and to explore the interrelationship between role preference and demographic variables.

\section{RESULTS}

Two hundred and thirty adults with asthma (152 from primary care) were interviewed. Their demographic characteristics and asthma severity are shown in table 1 . Deliberate inclusion of "difficult to reach" groups impacted on recruitment, with rates ranging from $25 \%$ in the most socially deprived site to over $60 \%$ in the most affluent site. The overall recruitment rate was 232/769 (30.2\%); data from two patients were excluded as incomplete. Only 10 respondents described their ethnicity as other than "white British"; this was representative of the study localities. Although the sample had a good age range, recruitment was a little disappointing in those aged 25 years or less who made up only $4.8 \%$ of the sample $(n=11)$. The ratio of men to women was as would be expected in an adult asthma sample. Application of Coombs' unfolding theory ${ }^{22}$ confirmed that the $\mathrm{CPS}^{7}$ was transferable to asthma.

\section{Preferred decisional role}

The collaborative role (C) was the single most popular, selected by just over one third of respondents (table 2). More respondents preferred one of the passive roles (card D or E, $40.4 \%$ ) than one of the active roles (card A or B, 23.9\%). Card A was least preferred by $126(54.8 \%), \mathrm{E}$ by $98(42.6 \%)$, compared with B $(n=3$ respondents), C $(n=1)$, and D $(\mathrm{n}=2)$. Box 2 presents common rationales for role preference and box 3 lists typical circumstances under which role preference would change.

\section{Perceived decisional role}

Most respondents ( $n=166,72.2 \%$ ) considered that their role was either semi-passive or passive, so that they had little active involvement in treatment decisions (table 2).

\section{Congruence between most preferred and perceived role}

Only one third of respondents $(\mathrm{n}=77,33.5 \%)$ perceived themselves as attaining their most preferred decisional role, while over half $(\mathrm{n}=127,55.2 \%)$ were less involved than they would have preferred (table 2 ). The more active the person's preferred role, the less likely they were to perceive themselves as attaining it. Agreement between most preferred and perceived roles was low (kappa $=0.13)$, and agreement between role types (active, collaborative or passive) was only fair $($ kappa $=0.21) .^{24}$

\section{Facilitators of and barriers to participation}

Patient related, professional related, and organisational barriers to and facilitators of participation were identified, with patient-professional relationships and lack of time being most commonly commented upon (box 4). Comments regarding "lack of contact with health professionals" typically referred to receipt of repeat prescriptions. 
Table 1 Demographic characteristics and asthma severity of the sample $(n=230)$

\begin{tabular}{|c|c|c|c|}
\hline Characteristic & $\begin{array}{l}\text { Primary care } \\
(\mathrm{n}=152,66.1 \%)\end{array}$ & $\begin{array}{l}\text { Specialist respiratory centre } \\
(\mathrm{n}=78,33.9 \%)\end{array}$ & $\begin{array}{l}\text { Total sample } \\
(n=230)\end{array}$ \\
\hline \multicolumn{4}{|l|}{ Age (years) } \\
\hline Mean & 51.2 & 53.3 & 51.9 \\
\hline Median & 50.5 & 54.0 & 51.5 \\
\hline SD & 16.7 & 13.4 & 15.6 \\
\hline Range & $19-94$ & $22-79$ & $19-94$ \\
\hline \multicolumn{4}{|l|}{ Sex } \\
\hline Men & $62(40.8)$ & 35 (44.9) & $97(42.2)$ \\
\hline Women & 90 (59.2) & $43(55.1)$ & $133(57.8)$ \\
\hline \multicolumn{4}{|l|}{ Duration of condition (years) } \\
\hline Mean & 23.4 & 18.9 & 21.9 \\
\hline Median & 18.5 & 15.0 & 17.3 \\
\hline SD & 17.6 & 15.9 & 17.2 \\
\hline Range & $0.5-77$ & $1-62$ & $0.5-77$ \\
\hline \multicolumn{4}{|l|}{ Highest level of education } \\
\hline No formal qualifications & $32(21.1 \%)$ & $17(21.8 \%)$ & $49(21.3 \%)$ \\
\hline Sub-degree & $44(28.9 \%)$ & $22(28.2 \%)$ & $66(28.7 \%)$ \\
\hline Degree and above & $33(21.8 \%)$ & $12(15.4 \%)$ & $45(19.6 \%)$ \\
\hline Professional/work related & $43(28.3 \%)$ & $27(34.6 \%)$ & $70(30.4 \%)$ \\
\hline \multicolumn{4}{|l|}{ Socioeconomic group (after NS-SEC ${ }^{20}$ ) } \\
\hline $\begin{array}{l}1 \text { (higher managerial and } \\
\text { professional) }\end{array}$ & $29(19.1 \%)$ & $14(17.9 \%)$ & $43(18.7 \%)$ \\
\hline $\begin{array}{l}2 \text { (lower managerial and } \\
\text { professional) }\end{array}$ & $22(14.5 \%)$ & $8(10.3 \%)$ & $30(13.0 \%)$ \\
\hline 3 (intermediate) & $10(6.6 \%)$ & $5(6.4 \%)$ & $15(6.5 \%)$ \\
\hline $\begin{array}{l}4 \text { (small employers and own } \\
\text { account workers) }\end{array}$ & $1(0.7 \%)$ & 0 & $1(0.4 \%)$ \\
\hline 5 (lower supervisory and technical) & $4(2.6 \%)$ & $1(1.3 \%)$ & $5(2.2 \%)$ \\
\hline 6 (semi-routine) & $20(13.2 \%)$ & $7(9.0 \%)$ & $27(11.7 \%)$ \\
\hline 7 (routine) & $10(6.6 \%)$ & 8 (10.3\%) & $18(7.8 \%)$ \\
\hline $\begin{array}{l}8 \text { (never worked and long term } \\
\text { unemployed*) }\end{array}$ & $8(5.3 \%)$ & $8(10.3 \%)$ & $16(7.0 \%)$ \\
\hline Student & $3(2.0 \%)$ & $2(2.6 \%)$ & $5(2.2 \%)$ \\
\hline Retired & $45(29.6 \%)$ & $25(32.1 \%)$ & $70(30.5 \%)$ \\
\hline \multicolumn{4}{|l|}{ Asthma severity (after BTS/SIGN ${ }^{6}$ ) } \\
\hline Step 1 (mild intermittent asthma) & $20(13.2 \%)$ & $3(3.8 \%)$ & $23(10.0 \%)$ \\
\hline $\begin{array}{l}\text { Step } 2 \text { (introduction of regular } \\
\text { preventer therapy) }\end{array}$ & $68(44.7 \%)$ & $24(30.8 \%)$ & $92(40.0 \%)$ \\
\hline Step 3 (add-on therapy) & $37(24.3 \%)$ & 18 (23.1\%) & $55(23.9 \%)$ \\
\hline $\begin{array}{l}\text { Step } 4 \text { poor control on moderate } \\
\text { dose of inhaled steroid + add-on }\end{array}$ & $25(16.4 \%)$ & $25(32.1 \%)$ & $50(21.7 \%)$ \\
\hline $\begin{array}{l}\text { therapy: addition of tourth drug) } \\
\text { Step } 5 \text { (continuous or frequent } \\
\text { use of oral steroids) }\end{array}$ & $2(1.3 \%)$ & $8(10.3 \%)$ & $10(4.4 \%)$ \\
\hline
\end{tabular}

\section{Relationship between most preferred role and demographic variables/asthma severity}

Decisional role preferences were compared by demographic group and severity of asthma (table 3 ). Preferences were similar for patients from primary care and secondary care $\left(\chi^{2}\right.$ test for trend $=0.26, \mathrm{df}=1, \mathrm{p}=0.61$ ) and there was no significant association with sex $\left(\chi^{2}\right.$ test for trend $=1.94$, $\mathrm{df}=\mathrm{l}, \mathrm{p}=0.16)$, duration of condition (Kendall's $\operatorname{tau}_{\mathrm{b}}=$ $-0.03, \mathrm{p}=0.54$ ), or severity of asthma (Kendall's tau $\mathrm{b}_{\mathrm{b}}=0.07$, $\mathrm{p}=0.22)$. There were significant associations between role preferences and age (Kendall's tau $\left.\mathrm{b}_{\mathrm{b}}=0.18, \mathrm{p}<0.001\right)$, highest level of education $\left(\chi^{2}=30.27, \mathrm{df}=12, \mathrm{p}=0.003\right)$, and socioeconomic group (for the 139 in current employment, Kendall's $\left.\operatorname{tau}_{\mathrm{b}}=0.24, \mathrm{p}<0.001\right)$. Older individuals typically (but not exclusively) preferred a more passive role, as did those with fewer educational qualifications and those from less skilled occupational groups. The result for educational qualifications should be interpreted with caution since most individuals with no qualifications were also above the mean age. Likewise, the smaller group sizes should be considered when interpreting findings for socioeconomic group.

Table 2 Most preferred and perceived role, with comparison between the two $(n=230)$

\begin{tabular}{|c|c|c|c|c|c|c|}
\hline \multirow[b]{2}{*}{ Most preferred role } & \multicolumn{6}{|l|}{ Perceived role } \\
\hline & $\begin{array}{l}\text { A } \\
\text { (fully active) }\end{array}$ & $\begin{array}{l}\text { B } \\
\text { (semi-active) }\end{array}$ & $\begin{array}{l}\text { C } \\
\text { (collaborative) }\end{array}$ & $\begin{array}{l}\text { D } \\
\text { (semi-passive) }\end{array}$ & $\begin{array}{l}\text { E } \\
\text { (fully passive) }\end{array}$ & Total \\
\hline A (fully active) & 1 & 3 & 1 & 2 & 7 & $14(6.1 \%)$ \\
\hline B (semi-active) & 2 & 7 & 16 & 8 & 8 & $41(17.8 \%)$ \\
\hline C (collaborative) & 0 & 4 & 21 & 36 & 21 & $82(35.7 \%)$ \\
\hline D (semi-passive) & 1 & 1 & 5 & 29 & 25 & $61(26.5 \%)$ \\
\hline E (fully passive) & 0 & 0 & 2 & 12 & 18 & 32 (13.9\%) \\
\hline Total & $4(1.7 \%)$ & $15(6.5 \%)$ & 45 (19.6\%) & 87 (37.8\%) & 79 (34.4\%) & 230 \\
\hline
\end{tabular}

Numbers in bold (on leading diagonal) indicate that perceived role equals most preferred role. Numbers in italics (above leading diagonal) indicate that perceived role is less active than most preferred role. Numbers in normal font (below leading diagonal) indicate that perceived role is more active than most preferred role. 
Box 2 Common rationales for role preference: illustrative data extracts

Active role (cards A and B)

"Rightly or wrongly, I am inclined to like to make decisions for myself. I'm not saying I'm right - I just like to make the choice myself, to be honest." (PC098, preference order $A B C D E)$

"Because I think it's about personal choice. I've been an asthmatic since I was a baby. And I was basically addicted to my Ventolin - I was getting through four a month! And nobody picked it up. So I changed GP and it was picked up. I went to the GP and said: 'I think I'm addicted and I want to change it' and they said 'Fine' .... And I think it's too easy to fall into the trap of letting the doctor make all the decisions for you, whereas I tend to have a more equal relationship with my doctor - I go in and tell him what's wrong and what I want!" [laughs]. (PC125, preference order $A B C D E)$

"I suppose because you've got more control over your own destiny. I like to be able to question why and feel that I've had a say, I suppose, I wouldn't like to feel that I've had something imposed on me." (SC055, preference order BCDEA)

"Past experience - we [self and spouse] have been in contact with lots of doctors and sometimes doctors make the wrong decision. You come to a point where you feel you've tried everything and you've got to make your own decisions. I do respect doctors' opinions, but they have got to respect yours. You're just paying them to do a job like anyone else - I think a lot of people forget that." (SCO41, preference order BACDE)

\section{Collaborative role (card C)}

"I want to be involved - to be involved in knowing what's happening to my body and in what medications I am using. Especially with medicines - I like to be able to feedback on how they are affecting me. It's a two-way thing." (SCO2, preference order CDEBA)

"Because obviously I haven't got the knowledge, the range or depth of knowledge to make a decision on my own. And if it's yourself, you're not completely objective either. But it's my body, so I should have a very big say in what happens. So a balance is probably best. There's no point in me taking the final decision, as I haven't got the correct knowledge for that." (PCO3, preference order CBADE)

\section{Passive role (cards D and E)}

"Well, I mean, that's what they're there for, that's what they're trained for. I'd like to have a little say, but at the end of the day, it's his decision. It's no use going to a specialist or consultant if you're not going to take his advice." (PC138, preference order DCEBA)

"Well, two reasons - from his point of view, he has got the expertise, but I could bring my own individual symptoms and suggest occasionally could I try things. But obviously, the final decision is down to him, after my input." (SC030, preference order DCEBA)

"Because I haven't got a clue about medications. And obviously, my doctor's been in the field for years and knows what he's talking about, so obviously you're going to trust him." (SC014, preference order ECDBA)

"I don't believe I'm competent to influence the decision too much. So I trust someone who's been to medical school for seven years, unlike me, who hasn't! ... I have touching faith in professionals. I accord them the respect in their field that I hope and expect they'd accord me in mine. So it's a matter of professional courtesy." (PC033, preference order EDCBA)
Box 3 Common themes regarding circumstances under which respondents' role preferences would change

Role preference would be more active than usual if:

- The treatment was not perceived to be working or was perceived to be causing harm

- The respondent lost "faith" or "confidence" in the doctor

- The doctor was unfamiliar or was not their "usual" doctor

- The respondent knew more about their condition and the available treatments

- The decision was a "serious one" (for example, one with potential hazards, long term implications)

Role preference would be less active than usual if:

- The respondent was seriously ill (for example, having an asthma attack) or physically incapacitated (for example, unconscious) at the decisional juncture

- The respondent was mentally incapable of participating in the decision making (for example, due to dementia)

- The respondent was faced with a decision regarding an aspect of care (for example, a treatment) about which they felt they knew little

- The disease was a "more serious" one than asthma (for example, cancer)

- The respondent felt there was only one option available/suitable, hence there was not really a choice to be made

Various ordinal logistic regression models were fitted to explore the prediction of most preferred role from age and highest level of education. The results suggested that the effect for age adjusted for education remained highly significant, while that for education adjusted for age tended to be significant for degree level and above and, to a lesser extent, for professional or work related qualifications compared with no formal qualifications.

\section{DISCUSSION}

The findings of this study confirm the results of previous work $^{10-12}$ in showing that respondents had identifiable preferences, from active through to passive, regarding their level of participation in treatment decision making. The study adds new knowledge regarding contributors to these preferences, the role of demographic variables in determining role preferences, and the extent to which patients' preferences were met. While the focus of this study was asthma, the findings address aspects of provider-patient consultations which may have relevance in other long term health problems.

The substantial mismatch between respondents' most preferred and perceived decisional roles is the most notable finding in this study. This was especially marked in those preferring an active role. Most respondents felt they had little or no say in treatment decisions and, in common with the sample studied by Adams et al, ${ }^{11}$ many would have liked to be more involved. The communication skills of professionals are considered to be central to facilitating patient participation. $^{25}$ Our findings confirm this view, and many respondents identified communication as an area requiring improvement. Furthermore, it appears that, rather than 
Box 4 Common themes regarding facilitators of and barriers to patient participation in treatment decision making

\section{Facilitators}

- Having sufficient time during consultations

- Continuity of care

- Having a good relationship with the health professional

- Having had asthma for a long time

- Patients having sufficient knowledge and information

- Patients being assertive/expressing their views and preferences

- Health professionals being willing to listen and to acknowledge patients' perspectives and insights

\section{Barriers}

- Patients' lack of knowledge regarding the condition and its treatment

- Personal characteristics of the patient (for example, lack of assertiveness, age, ability to understand)

- Patient being in a life threatening situation

- Health professionals with poor interpersonal skills

- Health professionals' unwillingness to listen or to accept patients' expertise

- Lack of time during consultations

- Lack of contact with health professionals (for example, no regular review, receipt of repeat prescriptions)

recognising and responding to the range of patient preferences regarding involvement in treatment decisions, health professionals may be adopting a "one size fits all" approach. These findings suggest a need for professional education regarding partnership working. Possible approaches include training in patient centred communication skills, ${ }^{25}$ workshops (jointly with service users), ${ }^{26}$ use of taped consultations to allow feedback and discussion of patient involvement, ${ }^{27}$ involvement of health service users in professional education, ${ }^{28}{ }^{29}$ and use of specific shared decision making training packages or programmes. ${ }^{29}{ }^{30}$ Research to improve understanding of healthcare providers' perspectives on shared decision making in asthma, particularly perceived barriers, would be of value. A comparison of providers' and patients' perspectives on the same treatment decision would also be worthwhile, especially as work elsewhere suggests that health professionals are poor at identifying patients' needs and preferences. ${ }^{431}$

Some patients felt they could not participate in decisions as they lacked knowledge, experience or assertiveness, while others had no expectation of participating in treatment decisions-a finding reported elsewhere. ${ }^{3} 910$ This suggests a need for enhanced patient education and awareness raising with regard to partnership working. The Department of Health's "Expert Patient" programme, ${ }^{5}$ itself based on the work of Lorig et al, ${ }^{3233}$ is one example of such an initiative. With regard to asthma, increased provision of personalised, written asthma action plans-currently only provided to 3\% of patients ${ }^{34}$ — could be one means of facilitating patient involvement.

While some respondents highly valued the time saving and simplicity afforded by repeat prescriptions, others felt isolated and reported lacking opportunities to discuss their treatment and progress with health professionals. This was interesting, as all the primary care sites had at least one individual with a

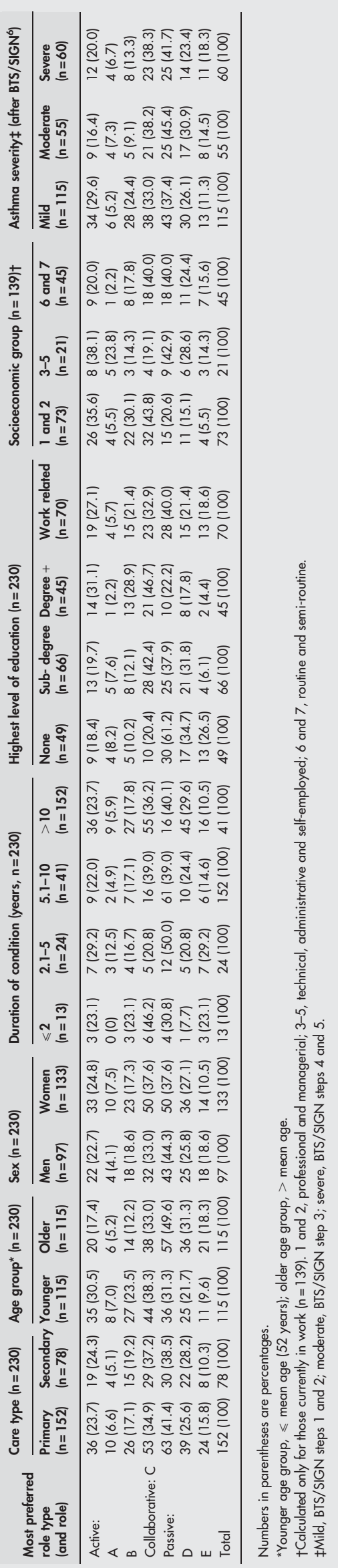


special interest in asthma care and/or a nurse led asthma clinic.

The most commonly cited organisational barrier to patient participation was lack of time during consultations. It has been suggested that a consultation of at least 20 minutes' duration is required to facilitate patient participation. ${ }^{35}$ With health care under increasing pressure, it is hard for health professionals to find time for asthma patients who need it, suggesting the need to consider alternative means of providing asthma patient review and education. Telephone consultations have been shown to be time efficient and cost effective means of providing asthma education and review management. ${ }^{36}$ Other alternatives such as lay/peer led asthma patient education need to be validated before widespread introduction.

Asthma is a long term condition (mean 22 years in this sample) in which self-management and participation in treatment decision making are encouraged-for example, recent guidelines ${ }^{6}$ recommend providing individualised written asthma action plans as these promote self-management and involvement in decision making with resultant improvement in outcomes. ${ }^{126}$ It was therefore interesting to see that some $40 \%$ of patients most preferred one of the passive decisional roles (card D or E from the CPS). These patients' decisional role preferences might seem to be at variance with current thinking among health professionals, policy makers, and patient advocacy groups. ${ }^{1-5}$ However, examination of rationales for role preference reveals a more complex picture. The most passive option (card E) was least preferred by nearly half the respondents. Furthermore, twice as many of those preferring a passive role chose card D-which involves some, if limited, patient involvement-rather than card $\mathrm{E}$ where the patient entirely defers decision making to health professionals. Thus, most respondents wanted some input into decision making. Typically, this extended to individuals feeling included in the decision and having their views respected. While most respondents in this sample were happy to defer overall control of treatment decision making to professionals, our data encourage the notion of partnership.

It is important to identify individual role preferences. Role preference was not strongly associated with demographic variables and may change at different times and in different situations; thus, an individual who would wish to be passive in an emergency situation might feel able to be more actively involved in treatment decision making on a day to day basis.

The low overall response rate is acknowledged as a limitation. However, this largely resulted from inclusion of "difficult to reach" groups. Given the higher response rates from affluent areas, had we not over-represented socially deprived areas in the primary care sites (by having five out of 10 from socially deprived areas), responses would have been very skewed towards affluent, well educated individuals whose views may not have been representative of the full social and educational spectrum. As can be seen from table 1 , our chosen approach ensured that viewpoints from a range of educational and social backgrounds were represented. This cross sectional study involved only adults and was racially homogenous. Further work is needed in children/adolescents and also in other ethnic groups. Longitudinal data would also show how role preferences change over time and in different circumstances.

In conclusion, the findings from this study suggest that adults with asthma are readily able to identify their preferred level of involvement in treatment decision making and that this could not be predicted from demographic variables or measures of disease severity. Most patients wished to have some involvement in treatment decision making, but not necessarily to control it. Most considered that they were less involved in treatment decision making than they would have preferred. Respondents identified patient related, provider related, and practical/organisational barriers to participation, highlighting the need for professional and patient education regarding partnership working, skilful communication, and innovative approaches to service delivery

\section{Authors' affiliations}

A-L Caress, K Beaver, K Luker, M Campbell, School of Nursing, Midwifery and Social Work, University of Manchester, Manchester M13 9PL, UK

A Woodcock, North West Lung Centre, Wythenshawe Hospital, Manchester M23 9LT, UK

This project was funded through the NHS National R\&D Programme on Asthma Management (Grant Number AM2/10/059) and administered by the National Asthma Campaign (now Asthma UK). The views expressed are those of the authors. The support of both of agencies is gratefully acknowledged, as is the generous contribution of the study sites and participants.

Conflict of interest: none for any author

\section{REFERENCES}

1 Gibson PG, Coughlan J, Wilson AJ, et al. Self-management education and regular practitioner review for adults with asthma (Cochrane Review CD 001005). In: The Cochrane Library. Issue 3. Oxford: Update Software, 2001.

2 Partridge MR, Hill SR. Enhancing care for people with asthma: the role of communication, education, training and self-management. Eur Respir J 2000; 16:333-48.

3 Guadagnoli E, Ward P. Patient participation in decision-making. Soc Sci Med 1998:47:329-39.

4 Coulter A. Partnerships with patients: the pros and cons of shared clinical decision-making. J Health Serv Res Policy 1997;35:276-81.

5 Department of Health. The expert patient: a new approach to chronic disease management for the 21 st century. London: Department of Health, 2001.

6 British Thoracic Society/Scottish Intercollegiate Guidelines Network. British guideline on the management of asthma. Thorax 2003;58(Suppl I):i1-94.

7 Degner LF, Sloan JA, Venkatesh P. The Control Preferences Scale. Can J Nurs Res 1997;29:21-43.

8 Beaver K, Bogg J, Luker KA. Decision making role preferences and information needs: a comparison of colorectal and breast cancer. Health Expectations 1999;2:266-76.

9 Kenny P, Quine S, Shiell A, et al. Participation in treatment decision-making by women with early stage breast cancer. Health Expectations 1999:2:159-68.

10 Caress A-L, Luker KA, Woodcock AA, et al. A qualitative exploration of treatment decision-making role preference in adult asthma patients. Health Expectations 2002;5:223-5.

11 Adams RJ, Smith BJ, Ruffin RE. Patient preferences for autonomy in decision making in asthma management. Thorax 2001;56:126-32.

12 Gibson PG, Talbot PI, Toneguzzi RC, the Population Medicine Group 91C. Self-management, autonomy and quality of life. Chest 1995;107:1003-8.

13 Rona RJ. Asthma and poverty. Thorax 2000;55:239-44.

14 Neville RG, McCowan C, Hoskins G, et al. Cross-sectional observations on the natural history of asthma. Br J Gen Pract 2001;51:361-5.

15 Enright PL, McClelland RL, Newman AB, et al. Under-diagnosis and undertreatment of asthma in the elderly. Cardiovascular Health Study Research Group. Chest 1999;116:606-13.

16 Partridge MR. In what way may race, ethnicity or culture influence asthma outcomes? Thorax 2000;55:175-6.

17 Griffiths C, Kaur G, Gantley M, et al. Influences on hospital admission for asthma in south Asian and white adults: qualitative interview study. BNJ 2001;323:962-?

18 De Marco R, Locatelli F, Sunyer J, et al. Differences in incidence of reported asthma related to age in men and women: a retrospective analysis of the data of the European Respiratory Health Survey. Am J Respir Crit Care Med 2000;162:68-74.

19 Caress A-L, Luker KA, Ackrill P. Patient-sensitive treatment decision-making preferences and perceptions in a sample of renal patients. NT Research 1998:3:364-72.

20 Office for National Statistics. New social and occupational classifications: National Statistics Socio-economic Classification (NS-SEC). http:// www.ons.gov.uk, 2000

21 Strauss AL, Corbin J. Basics of qualitative research: grounded theory procedures and techniques. 2nd ed. London: Sage, 1998.

22 Coombs CH. A theory of data. New York: Wiley, 1964.

23 Sloan JA, Yeung A. A manual for implementing Coombs' unidimensional unfolding model for paired comparisons data. Manitoba Nursing Research Institute Technical Report No 12. Manitoba, Canada: University of Manitoba, 1994.

24 Altman DG. Practical statistics for medical research. London: Chapman and Hall/CRC, 1991. 
25 Roter $\mathbf{D}$. The medical visit context of treatment decision-making and the therapeutic relationship. Health Expectations 2000;3:17-25.

26 Lamont L, Levenson R. Patients, carers and staff: talking to each other to improve healthcare service delivery. Health Expectations 2001;4:140-3.

27 Stevenson FA, Barry CA, Britten N, et al. Doctor-patient communication about drugs: the evidence for shared decision-making. Soc Sci Med 2000;50:829-40.

28 Pyke J, Lancaster J, Pritchard J. Training for partnership. Psychiatr Rehabil J 1997;21:64-6.

29 Towle A. Shifting the culture of continuing medical education: what needs to happen and why is it so difficult? J Cont Educ Health Professions 2000;20:208-18.

30 Davis RE, Dolan C, Thomas S, et al. Exploring doctor and patient views about risk communication and shared decision-making in the consultation. Health Expectations 2003;6:198-207.
31 Jones A, Pill R, Adams S. Qualitative study of views of health professionals and patients on guided self-management plans for asthma. BMJ 2000;321:1507-10.

32 Lorig KR, Sobel DS, Ritter PL, et al. Effect of a self-management program on patients with chronic disease. Effect Clin Pract 2001;4:256-62.

33 Lorig KR, Sobel DS, Stewart AL, et al. Evidence suggesting that a chronic disease self-management program can improve health status while reducing hospitalization: a randomized trial. Med Care 1999;37:5-14.

34 Smith A, Partridge MR. Greater expectations? Asthma J 2000;5:106-7.

35 Adams RJ, Smith BJ, Ruffin RE. Impact of the physician's participatory style on asthma outcomes and patient satisfaction. Ann Allergy Asthma Immunol 2001;86:263-71

36 Pinnock H, Bawden R, Proctor S, et al. Accessibility, acceptability, and effectiveness in primary care of routine telephone review of asthma: pragmatic, randomised controlled trial. BMJ 2003;326:477-9.

\section{Committee on Publication Ethics Seminar 2005 \\ Friday 11 March 2005, 9.30 am - 5 pm, BMA House, London}

This year's seminar will focus on COPE's new Code of Conduct for Editors and interactive workshops on common ethical and editorial dilemmas. The seminar is for editors, authors, and all those interested in increasing the standard of publication ethics.

The Code aims to set a new basic standard for the ethical conduct of editors and sets out guidelines for quality and correcting the record, standing by decisions made, ethics committee approval, consent for publication confidentiality of submitted material, guidance to authors, pursuing misconduct, relationship to publishers, owners, and advertisers, and conflict of interest. The code also creates a mechanism to refer a complaint to COPE if an editor has breached the code.

The seminar will include:

- The new Code of Conduct for Editors

- Dr lona Heath, Chair BMJ Ethics Committee-research, audit, and ethics committee approval

- COPE's new website-full text and keyword searching for COPE's advice on specific issues, for example research misconduct, conflict of interest, and deception

- Interactive workshops-common ethical and editorial dilemmas for editors

- Opportunities to network with other editors and share your experiences and challenges

The seminar is free for COPE members and $£ 30.00$ for non-members. Numbers are limited and early booking is advisable. For registrations or more information please contact Sam Knottenbelt at cope@bmigroup.com or call 0207383 6602. For more information on COPE see www.publicationethics.org.uk/ 